\title{
Climatology of nocturnal rainfall for northeast Kansas, 1950-2012
}

\section{Ian M. Howard and John Harrington, JR.}

\author{
Department of Geography, Kansas State University, Manhattan, Kansas \\ ihoward@ksu.edu-jharrin@ksu.edu
}

\begin{abstract}
Nighttime rainfall has long been thought of as an important component to the central Great Plains hydroclimate during the wettest three-month period known as the "late spring - early summer precipitation maximum" from May-July (MJJ), though the climatological characteristics in Kansas are not very well documented in the literature. The nighttime rainfall characteristics are examined based on hourly precipitation data for Topeka, KS and other Kansas stations for a 63-year period from 1950-2012 for MayJuly. Nighttime rainfall is a major contributor to the overall moisture budget in the Great Plains, contributing over $50 \%$ of the overall rainfall total for the three-month period, with an increase in the percentage from May to July. Most nocturnal rainfall events initiate around the local midnight hour, with earlier start times in May compared to June and July. The greatest hourly precipitation tends to occur around the same time, with a gradual step down into the mid-morning hours. Geographically, areas in the eastern portion of the state receive more nighttime rainfall on average for all three months than areas to the west.
\end{abstract}

Key words: Rainfall, nocturnal precipitation, late spring-early summer precipitation maximum, Topeka

\section{INTRODUCTION}

The frequency and intensity of precipitation in the central Great Plains of the United States varies greatly throughout the year. In the spring and summer months, the region receives the bulk of its precipitation, with numerous nocturnal rainstorms contributing to this seasonal maximum. The warm-season precipitation maximum occurs in May, June and July (MJJ), and forms as a result of a number of atmospheric properties that combine to promote thunderstorm and rainfall activity across the Great Plains. The predominance of warm season nighttime rainfall in the Great Plains remains one of the interesting climatic features in North America (Trewartha 1981). During the warm season, the combination of intense surface heating (leading to a very steep environmental lapse rate), large influxes of near-surface moisture, as well as a location protected from oceanic influences would normally create a strong daytime maximum in diurnal rainfall. However, the Great Plains does not fit the mold, as warm season precipitation in the region has pronounced diurnal variability (Pitchford and London 1962; Balling 1985). Precipitation fluctuations are common on daily and sub-daily time scales in the region and exhibit a nocturnal peak, differing from the late afternoon maximum over most inland regions (Jiang et al. 2006). In the Great Plains more than $60 \%$ of summer (June-July-August) thunderstorms occur during 1800-0600 local standard time (LST), with over $50 \%$ of summer rains occurring during the period of 0000 0600LST (Pitchford and London 1962). Other studies have found that during the late spring early summer months, east of $101^{\circ} \mathrm{W}$, a distinct 0300-0500LST precipitation maximum exists (Riley et al. 1987). In terms of the intensity however; studies have shown that the 0100 local hour tends to be the time where the most precipitation falls (Tucker and Li 2009). In addition, Tucker and Li (2009) found that most storms occurred around 1700LST.

The timing of rainfall in the Great Plains has a distinct west-east pattern, as areas in the west experience the most precipitation 
during early-to-late-evening hours, whereas areas eastward receive the most precipitation after midnight. Atmospheric circulation, and subsequently precipitation during the late spring-early summer precipitation maximum profoundly influences agriculture and water resources in the central United States.

Circulation patterns, both on a local and larger-synoptic scale, influence the regional hydroclimate and precipitation distribution by modulating moisture availability for storms and the position and strength of storm tracks. In addition, the diurnal cycle of precipitation frequency and intensity has large effects on aspects of surface hydrology (e.g., runoff and evaporation). The diurnal variations modulate surface temperatures, and closely correlate with diurnal cycles of convection and cloudiness that can affect both solar and long-wave radiation fluxes (Aiguo et al. 1999). It has been well documented that the summer time nighttime rainfall in the central Great Plains results from Mesoscale Convective Systems (MCSs) or the largest class of these type of systems, Mesoscale Convective Complexes (MCCs) (Maddox 1980). During the warm season, as much as $30-70 \%$ of rainfall occurs as the result of MCCs and large MCS-related storms between the Rocky Mountains and Mississippi River. With these types of systems, the largest precipitation tends to occur in the right rear and right front quadrants (Fritsch et al. 1986; Kane et al. 1987.)

Though the nocturnal character of rainfall during the late spring - early summer precipitation maximum is a well-known phenomenon, climatological characteristics are not necessarily well documented in the scholarly literature. On a more regional scale in Kansas, little has been done analyzing the importance of nocturnal rainfall to the overall moisture supply. Moreover, much of the research has emphasized precipitation frequency rather than amounts. Understanding precipitation in the central Great Plains based on frequency analyzed on various temporal and spatial timescales will add an additional component the knowledge of diurnal precipitation variability in the region. In an agricultural region largely dependent on warm season precipitation, knowing the hydrologic processes can have important applications and implications to the agricultural sector particularly with the concerns associated with changes to the precipitation regime resulting from global climate change. Using hourly precipitation data for northeast Kansas, this study expands on the existing research by analyzing the diurnal variability of rainfall during the wettest threemonth period of the year. Key aspects analyzed include the climatological characteristics of nocturnal rainfall, the timing, duration, and intensity of rainfall based on data from Topeka, and finally facets of the spatial variability of nighttime rainfall across Kansas.

\section{Data ANd Methods}

Available hourly precipitation data from the National Climatic Data Center (NCDC) for Topeka from 1950-2012 provides a lengthy period that enables analysis of interannual variations and trends. Additionally, the 1950s decade offers important variations in the climatic record with two climatic anomalies: the devastating flood in 1951, known as "The Great Flood" that decimated areas of northeast Kansas, as well as the 1950s drought that ravaged much of the southern Great Plains.

Topeka's Municipal Airport was selected as the primary study site to analyze nocturnal rainfall, as it offers consistent and reliable hourly precipitation data for the study period. Spatial and temporal aspects of rainfall vary greatly in Kansas, particularly during the warm season when meso-scale convective storms are far more common. Use of additional observation stations allows the analysis to develop results that enable a more robust understanding of the spatial and temporal characteristics of nocturnal rainfall. Given the typical eastward propagation of thunderstorms in the central Great Plains during the late spring and early summer months, stations to the west and southwest of Topeka offer the best opportunity 


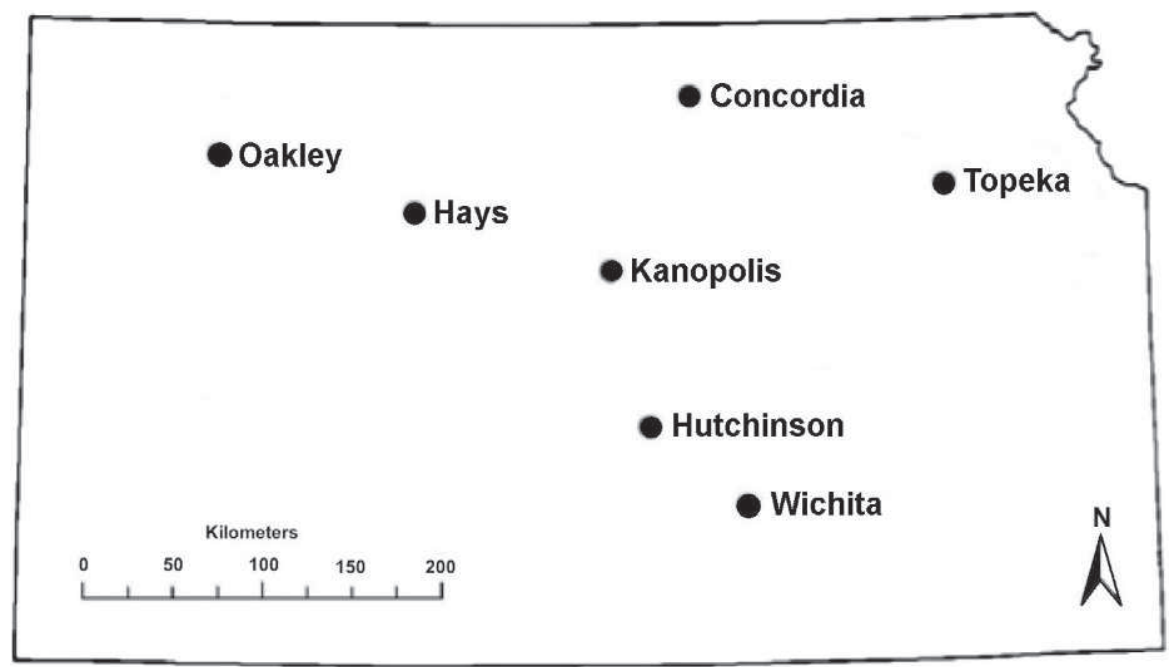

Figure 1. Location of stations used in this study with hourly rainfall data available from 1950-2012.

to better understand the spatial and temporal characteristics of nocturnal thunderstorms. Though many stations throughout Kansas do not contain hourly recorded precipitation data dating back to the early 1950 s, enough stations exist west of Topeka with hourly precipitation data spanning the entire 63 year period to make useful comparisons. The stations selected from Kansas include locations at Hays, Kanopolis Reservoir, Oakley, Concordia Blosser Municipal Airport, Arlington and Plevna (which will be referred to as Hutchinson), and Wichita MidContinent Airport (Fig. 1).

In years with no recorded hourly precipitation, data from nearby weather stations (generally within a 50 mile radius) were used. In all cases, data from multiple stations had to be acquired, due in large part to the sporadic coverage of hourly weather data for many stations (Howard 2013). Though the 19502012 period represents the longer time period, an additional time period for the diurnal cycle had to be included as well in order to analyze nocturnal rainfall on a day-by-day basis.

During MJJ the nocturnal period, from sunset to sunrise, extends from approximately 2100 to 0500LST. Based on previous research, to be considered a nocturnal event, the beginning of the rainfall had to register with the observations for the hours of 0100 and 0900LST. From the Topeka site, total rainfall for an event selected for further analysis had to exceed 0.25 inches $(6.35 \mathrm{~mm})$ to be considered a nocturnal event for this analysis. Investigation of hourly data from Topeka led to the conclusion that events less than 0.25 inches $(6.35 \mathrm{~mm})$ generally do not contribute much to the overall precipitation total, hence their exclusion in this research (Howard 2013). While storms may begin precipitating during the nine-hour window for the start time, often times the rains persisted past 0900LST. Conversely, numerous events form prior to 0100LST but the majority of the rainfall occurred between the hours of 0100LST and 0900LST. Special consideration based on their intensity had to be given to outlier events not fitting the designated nine-hour time period for nocturnal rainfall initiation. For instance, rainfall events beginning prior to 0100LST had to have at least $0.25(6.35 \mathrm{~mm})$ inches of rain occur during the designated time period for them to be considered nocturnal. Rainfall had to exceed a total of 0.10 inches $(2.54$ $\mathrm{mm})$ at the additional stations in order to be considered significant and related to the same event recorded at Topeka. Moreover, stations also had a three-hour time window before or after the first recorded rainfall at Topeka. For 


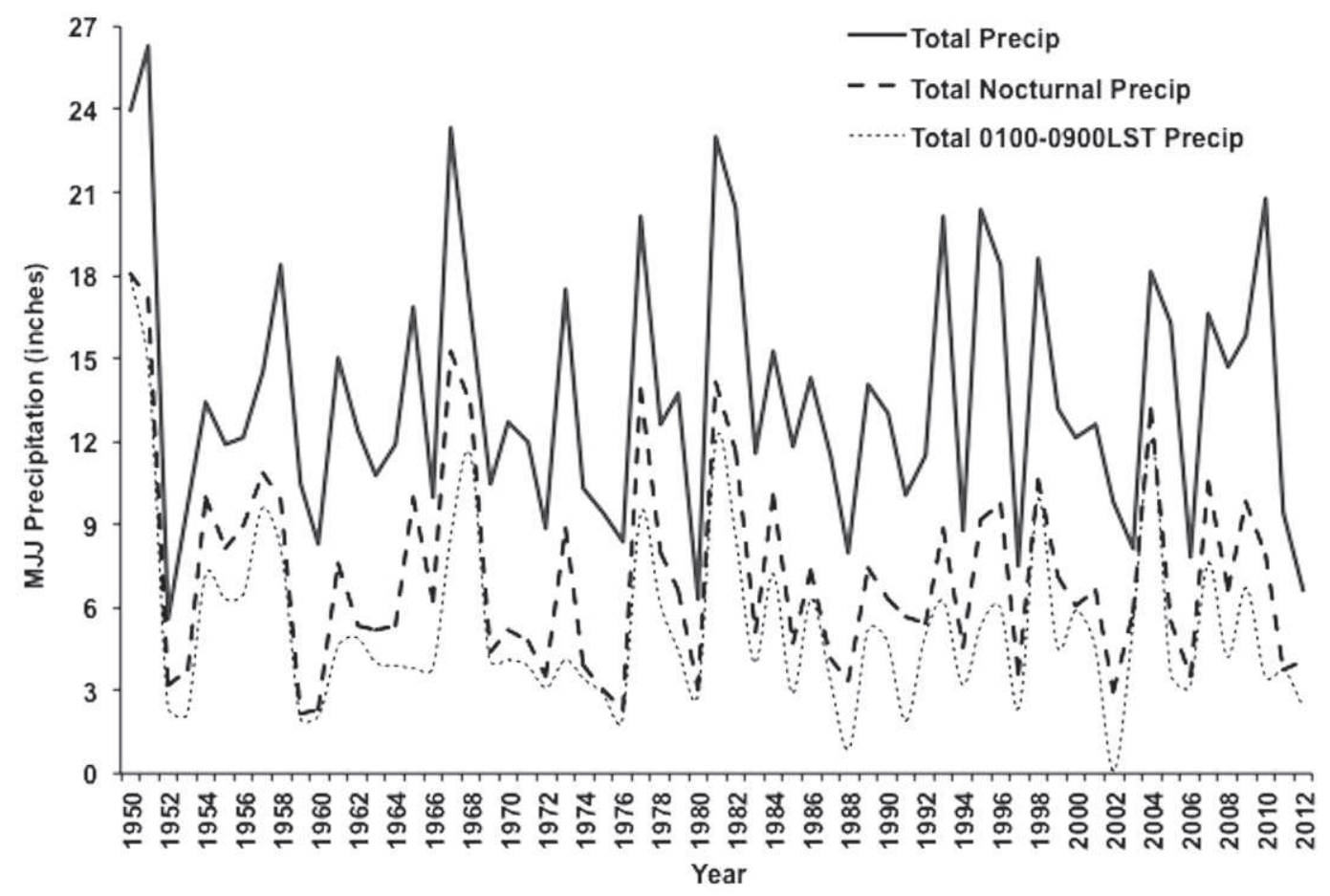

Figure 2. Variation in MJJ precipitation and the nocturnal component for Topeka, 1950- 2012.

instance, if Topeka first began recording rainfall at 0200LST, additional stations would need to report rain within the 2300-0400LST time range in order to be considered the same event.

\section{Results AND Discussion}

Climatological Characteristics - Based on the hourly precipitation data for the 63-year period, the Topeka Municipal Airport recorded 463 nighttime rainfall events of 0.25 inches $(6.35$ $\mathrm{mm}$ ) or more, an average of 7.35 events in MJJ each year. The number of nocturnal rainfall events for each month did not vary greatly (Table 1). However, the amount of nocturnal rainfall varied greatly on a year-to-year basis (Fig. 2). Three month total nocturnal rainfall varied from as high as 18 inches in 1950, to as low as three inches only two years later in 1952. By far, the back-to-back years of 1950 and 1951 represent the two wettest threemonth periods, largely a result of the nocturnal precipitation that occurred during the two years. Not surprisingly, this also results in the 1950s decade being the wettest decade on record despite the crippling 1950s drought. In fact, three out of top ten wettest nocturnal rainfall seasons occur during the 1950s.

The variability displayed in the precipitation data epitomizes the Great Plains climate during the warm season, as the region often experiences considerable swings on a yearby-year, and even a month-by-month basis. Combining the three months, nighttime rainfall contributed an average of 7.30 inches $(185.4 \mathrm{~mm})$ of the rainfall. On average, MJJ precipitation totals around 13.55 inches (344.2 $\mathrm{mm}$ ) based on the 1950-2012 climatology for the Topeka weather station. Therefore, nighttime rainfall accounts for over half (54\%) of the rainfall during the three-month time frame. However, the contribution of nighttime rainfall to the overall monthly precipitation total differs and increases during the MJJ period. During May, nighttime rainfall accounts for $46 \%$ (2.09 inches or $53.1 \mathrm{~mm}$ ) of the monthly rainfall budget. June and July 
Table 1. Nighttime rainfall characteristics for MJJ based on the selected rainfall data from Topeka, KS for 1950-2012.

\begin{tabular}{|l|c|c|c|c|c|c|}
\hline & $\begin{array}{c}\text { Nighttime } \\
\text { events } \\
\text { (> 0.25") }\end{array}$ & $\begin{array}{c}\text { Average } \\
\text { Monthly } \\
\text { Total } \\
\text { (inches) }\end{array}$ & $\begin{array}{c}\text { Average } \\
\text { Event } \\
\text { Size } \\
\text { (inches) }\end{array}$ & $\begin{array}{c}\text { Stan dard } \\
\text { Deviation }\end{array}$ & $\begin{array}{c}\text { Highest } \\
\text { Month } \\
\text { Total } \\
\text { (Year) }\end{array}$ & $\begin{array}{c}\text { \# of years } \\
\text { with no } \\
\text { nighttime } \\
\text { rainfall } \\
\text { events }\end{array}$ \\
\hline May & 154 & 2.09 & .85 & 1.63 & $\begin{array}{c}8.51 \\
(2007)\end{array}$ & 5 \\
\hline June & 156 & 2.74 & 1.07 & 2.32 & $\begin{array}{c}10.32 \\
(1977)\end{array}$ & 8 \\
\hline July & 153 & 2.47 & .99 & 2.41 & $\begin{array}{c}9.92 \\
(1950)\end{array}$ & 6 \\
\hline
\end{tabular}

have higher percentages of $54 \%$ (2.73 inches or $69.3 \mathrm{~mm})$ and $62 \%$ (2.47 inches or $62.7 \mathrm{~mm})$, respectively. Balling's (1985) analysis suggests an approximate $60 \%$ value for his analysis period of 1948-1977. Despite the three months having relatively similar characteristics in terms of the number of events over the 63-year period, June and July have a stronger nighttime rainfall signature, suggesting a transition in the nature of diurnal rainfall for June and July. The two months also appear to have more variation in terms of monthly nocturnal rainfall totals (Table 1). The standard deviation increases from 1.63 inches $(41.40 \mathrm{~mm})$ in May to a high of 2.41 inches $(61.2 \mathrm{~mm})$ in July.

\section{Timing Characteristics - Balling (1985)} indicates a 0300LST time for the maximum nocturnal rainfall frequency for northeast Kansas. Since many of the events extend for more than one hour, it is relevant to understand when these events start. Nocturnal rainfall events have distinct start time characteristics based on the month. May, June and July have differences in terms of the timing, duration and intensity of nocturnal precipitation. Analysis of the various temporal characteristics of nighttime rainfall is presented first, with an emphasis on the nature of the start times of nighttime rain and thunderstorm activity. During May, nocturnal rainfall tends to begin between 0000LST and 0200LST (43\% of events began during the three hour time frame). However, May is the only month with a relatively high percentage of events beginning prior to 0000LST (19\% of May events began before midnight, with roughly $11 \%$ beginning at 2200LST or 2300LST). For MJJ combined, Topeka recorded 29 events (out of 463 total) that started before the 2300LST (Fig. 3).

In June, rainfall tends to begin in the early morning hours around 0000LST, with 23\% (36 out of 156) of rainfall events beginning during that time. The hours of 0100-0300LST make up the majority of start times, as approximately $35 \%$ of all rainstorms began during the three-hour time frame. The number of events beginning the evening before 0000LST decreases from May into June, as only $16 \%$ of all June events begin prior to midnight. Since June rainfall rarely began in the early evening hours and persisted well into the morning hours, it suggests that either June rainfall did not fall as often in the late afternoon or early evening hours, or if it did atmospheric circulation mechanisms were not in place to maintain the storm so that it became a nocturnal event (Fig. 4).

July nocturnal rainfall events are more likely to begin in the early morning hours, with only $10 \%$ (15 out of 153 ) of the total events beginning before 0000LST. Since the midnight hour accounted for nearly a $1 / 5$ of all the events recorded for July, a decrease occurs in percentages for the 0100-0900LST time slot. With sunrise occurring around 0500LST, it is not surprising that the frequency of storms starting later in the latter half of the analysis period declines as solar radiation receipts on the tops of cumulonimbus clouds offset the longwave cooling from the tops of clouds. Only $63 \%$ of July nocturnal events began 

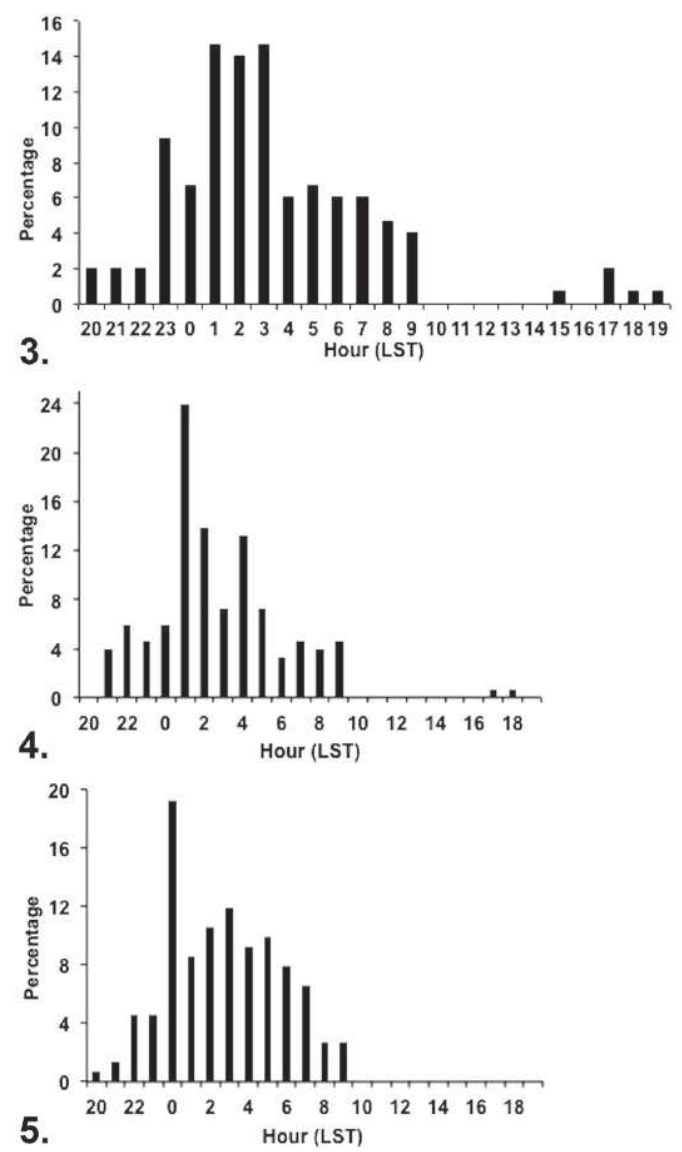

Figures 3, 4 and 5. Average start time for nocturnal rainfall events in Topeka for May (top), June (middle), and July (bottom).

during the study time window, compared to the $73 \%$ and $72 \%$ for May and June (Fig. 5). Taken together, for MJJ the majority of events begin between the hours of 0000 and 0300LST.

\section{Duration and Intensity Characteristics -}

The duration of nocturnal events was also a component of the statistical analysis. Event duration did not tend to vary by month, as the average length of precipitation events was 4.9, 4.8, and 4.7 hours for May, June and July, respectively. Perhaps the most revealing characteristic of the data has to do with the long duration of events initiating prior to 0100LST. These events display a distinct durational characteristic, as many of them persist well into the early morning hours. On average, events beginning prior to midnight last for over 7.5 hours. The intensity of the precipitation by hour tends to be at its highest for the hours around midnight, with the highest average precipitation occurring during the period of 2300-0200LST (Figs. 6-8). The hourly data suggests that heavier rains occur as the storms first move into the area. Howard (2013) provides details on the intensity calculations.

May has a wider time window due to the tendency for earlier storm initiation and longer lasting nature of storms during the month. For May, the highest average amount occurred the evening before at 2000LST ( 0.27 inches or $6.9 \mathrm{~mm}$ ) (Fig. 6) followed by another spike at 0100LST. The highest average precipitation in June and July occurs two hours later at the 2300LST time slot with an average of over 0.40 inches (10.2 mm) (Fig. 7), followed by a general decrease in average precipitation through the early morning hours with finally an increase coming in mid-morning. Thirty out of 46 events greater than 2.00 inches $(50.8 \mathrm{~mm})$ began at 0000LST or before, with half (15 out of 30) being recorded at 2200 and 2300LST. Therefore, the occurrence of an extremely heavy rainfall event at Topeka generally equates to the storm beginning the evening before and persisting well into the morning hours. Moreover, only 12 times during the entire study period did a storm event recorded during the hours of 0200LST and 0900LST exceed 2.00 inches $(50.8 \mathrm{~mm})$. The peak in rainfall prior to the midnight hour for May, June and July differs from previous literature, where it has been suggested that a peak in precipitation tends to occur around 0100LST (Tucker and Li 2009). Though, it is important to keep in mind the spatial and temporal differences between the studies that generate a different nocturnal rainfall intensity signature.

An interesting aspect of the data is a slight spike in hourly precipitation averages in the morning hours from 0600LST to 0800LST or at least not a decline, which might be an indication of a late night contribution of additional moisture associated with a nocturnal 


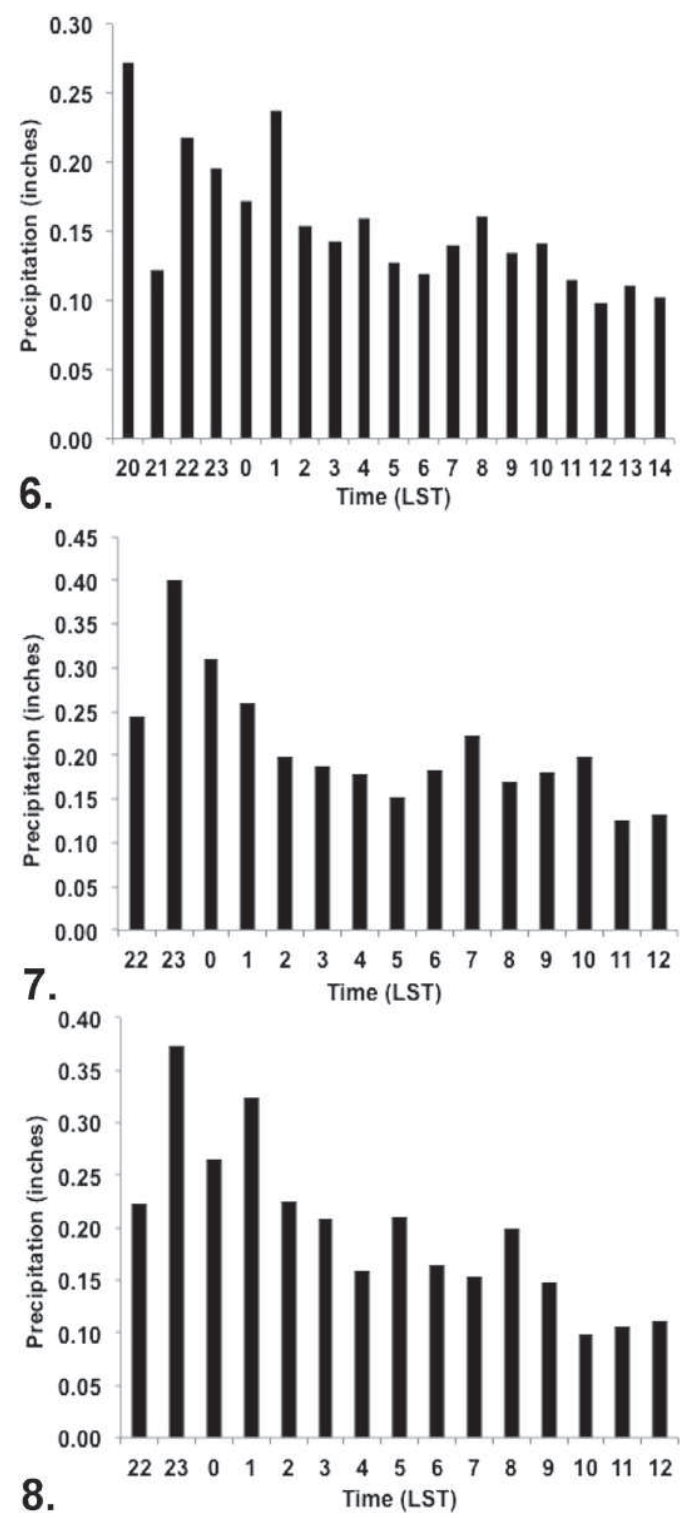

Figures 6,7 and 8 . Average precipitation for each hour for May (top), June (middle) and July (bottom).

low-level jet (Walters and Winkler 2001). Not surprisingly, the events that last for longer periods of time have larger precipitation totals associated with them. Previous literature has made the correlation that storm duration was the most important factor in determining the size of the event (Tucker and Li 2009). In fact, nocturnal events greater than 1.50 inches (38.1 $\mathrm{mm}$ ) on average last 8.2 hours. Conversely, events less than 1.50 inches $(38.1 \mathrm{~mm})$ persist for an average of 5.65 hours. As a result, many of the events that begin before 0100LST have the largest rainfall totals. Over $18 \%$ of all events were over 1.50 inches $(38.1 \mathrm{~mm})$ ( 86 out of 463 ) and these major rain events occur much more often in June and July (Table 2). Nocturnal events greater than 1.00 inches $(25.4 \mathrm{~mm})$ increase from around $25 \%$ in May to near 35\% in June and July. Moreover, nearly $25 \%$ of all rainfall events in June are over 1.50 inches $(38.1 \mathrm{~mm})$.

Spatial Characteristics - In addition to the temporal characteristics of nighttime rainfall, the spatial characteristics of nighttime events were analyzed using additional stations across Kansas. The spatial analysis can be divided into two parts. The first section analyzed the spatial properties of nighttime rainfall based on all 463 events recorded at Topeka. The subsequent section examined the climatological characteristics of nighttime rainfall for each of the selected stations, answering questions about the similarities and differences in nocturnal rainfall between Topeka and stations to west and south. Any rainfall recorded at a station exceeding 0.10 inches $(2.5 \mathrm{~mm})$ and occurring within the four-hour window of two hours prior to the first precipitation recorded at Topeka, to two hours later counted as a related event.

Nocturnal rainfall activity reported in Topeka shares a much stronger relationship with areas more directly west rather than to the southwest, as Concordia recorded more events every month than Wichita despite being similar distances apart from Topeka (Table 3). Concordia rainfall coincided with rainfall recorded at Topeka 294 out of 463 times (roughly $63 \%$ of the time). Kanopolis reported more related events than Wichita as well, though slightly less than Concordia (249 out of 463). Somewhat surprisingly, given their closer to proximity to moisture from the Gulf of Mexico, Wichita and Hutchinson had fewer events than Kanopolis and Concordia. Many storms during the late spring and earlysummer tend to be steered by southwesterly 
Table 2. Distribution of nocturnal rainfall events by rainfall size category for each month with corresponding percentages in parentheses.

\begin{tabular}{|c|c|c|c|c|}
\hline & May & June & July & MJJ \\
\hline $.25-.49$ inches & $58(37.7)$ & $41(26.1)$ & $45(29.7)$ & $144(31.3)$ \\
\hline $.5-.99$ inches & $57(37.0)$ & $62(39.5)$ & $51(33.6)$ & $170(36.6)$ \\
\hline $\mathbf{1 . 0 0 - 1 . 4 9}$ inches & $21(13.6)$ & $15(9.5)$ & $27(17.8)$ & $63(13.6)$ \\
\hline$>1.5$ inches & $18(11.0)$ & $39(24.9)$ & $29(19.1)$ & $86(18.5)$ \\
\hline
\end{tabular}

flow aloft and would migrate in a northeasterly direction. Perhaps these southwest-to-northeast moving storms tend to be different in character and do not exhibit a nocturnal character. Not surprisingly, the station in the far western part of the state had the lowest correlation with Topeka, as rainfall at Oakley only matched up with Topeka $29 \%$ (134 out of 463 ) of the time.

At Topeka, the number of events between the months did not vary greatly. Yet, almost every station displays a decrease in the number of events recorded for May-July that coincide with nocturnal rainfall recorded at Topeka. The exception is Concordia, where the number of corresponding noctural rains remains at approximately two out of every three events. These findings suggest that the progression from late-spring into early summer corresponds with a decrease in the spatial extent of nocturnal precipitation. Causes of the decreasing geographic coverage of storm rainfall may be the result of fewer frontal boundary-related events. A broad zone with multiple areas of thunderstorms associated with an approaching cold front would naturally increase the likelihood of a relationship between Topeka and additional stations to the west. Perhaps some storms in June and July form at night as a result of surface convergence associated with the northern extent of a southerly wind, creating more isolated clusters of storms rather than eastward propogating linear storms (Walters and Winkler 2001). An additional explanation may be that more storms are MCC or MCS related during June and July. Smaller-sized MCCs moving through the region later into the warm season would be an explanation for the decrease in spatial storm coverage from May to July.
Analysis of rainfall data for each station spanning the 1950-2012 period for MJJ provides important insights into nocturnal rainfall based on the latitude and longitude of each station. Places in western areas of Kansas do not experience nighttime rainfall as often as locations such as Topeka, due in large part to the differing diurnal cycle of thunderstorm development in the central Great Plains (Balling 1985). A general decreasing trend can be seen in both total precipitation and nighttime precipitation moving along the east-to-west transect from Topeka out to Oakley in the western part of the state. Total precipitation decreases by 4.97 inches (126.2 $\mathrm{mm}$ ) between the two stations, whereas total nighttime rainfall decreases by 3.72 inches $(94.5 \mathrm{~mm})$. Interesting details emerge from these data for May with Wichita and Concordia recording more nighttime rainfall, despite Topeka having a higher average of overall precipitation. The largest precipitation gradient (both total and nighttime) exists during June (Table 4). When examined as percentages, the east-west gradient can once again clearly

Table 3. Number of times that rainfall at other observation sites corresponded with nocturnal rainfall events at Topeka. Column headings provide the event frequency by month for Topeka in parentheses.

\begin{tabular}{|c|c|c|c|c|}
\hline & $\begin{array}{c}\text { May } \\
(\mathbf{1 5 4})\end{array}$ & $\begin{array}{c}\text { June } \\
(\mathbf{1 5 6})\end{array}$ & $\begin{array}{c}\text { July } \\
(\mathbf{1 5 3})\end{array}$ & $\begin{array}{c}\text { Total } \\
\mathbf{( 4 6 3 )}\end{array}$ \\
\hline Oakley & 49 & 45 & 40 & 134 \\
\hline Hays & 71 & 57 & 59 & 187 \\
\hline Kanopolis & 96 & 80 & 73 & 249 \\
\hline Concordia & 98 & 100 & 96 & 294 \\
\hline Hutchinson & 64 & 55 & 48 & 167 \\
\hline Wichita & 81 & 55 & 43 & 179 \\
\hline
\end{tabular}


Table 4. Climatological characteristics of MJJ rainfall and nighttime rainfall across Kansas. $(\mathrm{N})$ indicates nighttime rainfall average; $(T)$ indicates total average precipitation for that month.

\begin{tabular}{|c|c|c|c|c||cc||c|c|}
\hline & $\begin{array}{c}\text { May } \\
(\mathbf{N})\end{array}$ & $\begin{array}{c}\text { May } \\
(\mathbf{T})\end{array}$ & $\begin{array}{c}\text { June } \\
(\mathrm{N})\end{array}$ & $\begin{array}{c}\text { June } \\
(\mathrm{T})\end{array}$ & $\begin{array}{c}\text { July } \\
(\mathbf{N})\end{array}$ & $\begin{array}{c}\text { July } \\
(\mathrm{T})\end{array}$ & $\begin{array}{c}\text { MJJ } \\
(\mathbf{N})\end{array}$ & $\begin{array}{c}\text { MJJ } \\
(\mathbf{T})\end{array}$ \\
\hline Topeka & 2.09 & 4.46 & 2.74 & 5.11 & 2.47 & 3.98 & 7.30 & 13.55 \\
\hline Wichita & 2.25 & 4.11 & 2.49 & 4.58 & 2.17 & 3.56 & 6.91 & 12.26 \\
\hline Concordia & 2.33 & 4.19 & 2.14 & 4.07 & 2.23 & 3.74 & 6.70 & 12.00 \\
\hline Hutchinson & 1.49 & 4.04 & 1.98 & 4.44 & 1.61 & 3.71 & 5.08 & 12.18 \\
\hline Kanopolis & 1.63 & 3.87 & 1.71 & 3.82 & 1.87 & 3.50 & 5.21 & 11.19 \\
\hline Hays & 1.33 & 3.27 & 1.27 & 3.26 & 2.00 & 4.00 & 4.33 & 10.20 \\
\hline Oakley & 1.20 & 2.98 & 1.06 & 2.30 & 1.34 & 3.29 & 3.56 & 8.58 \\
\hline
\end{tabular}

be detected. Nighttime rainfall in the three eastern locales (Topeka, Wichita, Concordia) accounts for over $50 \%$ the overall rainfall total for the three month period whereas areas to the west have percentages lower than $50 \%$. For July, the nocturnal percentage of the total increases to $60 \%$ or more for the three eastern most locations. The east-west gradient across Kansas is evident in the MJJ nocturnal rainfall percentage, which decreases by over $10 \%$ from Topeka to Hays and Oakley. Geographic differences between eastern and western Kansas reinforce the idea that there are likely east-to-west differences in atmospheric processes related to the timing of storms and their access to moisture from the western Gulf of Mexico. Daytime convective heating in central Colorado along the Colorado Front Range promotes thunderstorm activity during the early afternoon hours. Afternoon thunderstorms in eastern Colorado may help destabilize the atmosphere in western Kansas as storms propogate eastward (Hales 1977).

\section{Summary}

Nocturnal rainfall contributes greatly to the local moisture supply in the central Great Plains during MJJ, the climatological late spring - early summer precipitation maximum for the region. A total of 463 nocturnal events in May-July were recorded during the 63-year period from 1950-2012, equating to around seven nocturnal events per season. Overall, just over $50 \%$ of the total MJJ precipitation at
Topeka falls during the nighttime hours from around 2100-0500LST, and the percentage increases from May to July. Initiation for nocturnal events tends to be earlier in the diurnal cycle in May compared to June and July.

Stations across Kansas shared the highest correlation among events during May, however most recorded a higher amount of nocturnal precipitation in either June or July. This reinforces the notion that while nighttime rainfall contributes a higher percentage to the moisture budget for areas in eastern Kansas, all regions across the state see an increase in nighttime rainfall later into the warm season, suggesting a change in synoptic character of rain storms as the warm season intensifies. One of the limitations of the study was the use of a limited number of stations to analyze rainfall. Rainfall in Kansas varies considerably in space and time; therefore use of one station raises concerns about how well it can accurately portray the characteristics of rainfall for a region. However, using Topeka as the primary station provided important insights into the characteristics of rainfall and its variations across the state and could be used a baseline for adding additional stations in future work.

For future work, using more stations with a long enough record would allow for a more complete assessment of the relative role of nocturnal rainfall in the central Great Plains, and perhaps provide an indication of whether changes in atmospheric processes are or have 
occurred in the region over time. This analysis of the importance of rainfall variability based on the diurnal cycle raises important questions about how climate change on a global to regional scale may result in changes in the characteristics of atmospheric processes that generate nighttime rainfall in the region. Will increased water vapor in the atmosphere related to a warmer Gulf of Mexico result in changes in storm intensity and frequency? Even slight changes to the timing or amount of nocturnal rainfall may impact water supplies for agriculture and other important economic sectors in Kansas. Further research might delve into the potential changes to the geography and timing of nocturnal rainfall and the related impacts, vulnerabilities, and the potential for citizens to adapt.

\section{ACKNOWLedgments}

We appreciate the helpful comments from the anonymous reviewers and thank the National Climatic Data Center for providing accessible hourly precipitation data for stations across Kansas. This work was supported by the National Science Foundation under Award No. EPS-0903806. Matching support from the State of Kansas through Kansas Technology Enterprise Corporation.

\section{Literature Cited}

Aiguo, D., Filippo, G. and Trenberth, K.E. 1999. Observed and model-simulated diurnal cycles of precipitation over the contiguous United States. Journal of Geophysical Research 104:6377-6402.

Balling, R.C. 1985. Warm season nocturnal precipitation in the Great Plains of the United States. Journal of Climate and Applied Meteorology 24:1383-1387.

Fritsch, J.M., Kane, R.J. and Chelius, C.R. 1986. The contribution of mesoscale convective weather systems to the warm-season precipitation in the United States. Journal of Climate and Applied Meteorology 25:1333-1345.
Hales, J.E. 1977. On the relationship of convective cooling to nocturnal thunderstorms at Phoenix. Monthly Weather Review 105:1609-1613.

Howard, I. 2013. A synoptic climatology of nocturnal rainfall events during May, June and July for northeast Kansas, 1950-2012. Masters Thesis, Kansas State University, Manhattan, $160 \mathrm{pp}$.

Jiang X., Ngar-Cheung, L. and Klein, S.A. 2006. Role of eastward propagating convection systems in the diurnal and seasonal mean of summertime rainfall over the U.S. Great Plains. Geophysical Research Letters 33, 6 pp.

Kane, R.J Jr., Chelius, C.R. and Fritsch, J.M. 1987. Precipitation characteristics of mesoscale convective weather systems. Journal of Applied Meteorology 26:1345-1357.

Pitchford, K.L. and London, J. 1962. The low-level jet as related to nocturnal thunderstorms over midwest United States. Journal of Applied Meteorology 1:43-47.

Riley, G.T., Landin, M.G. and Bosart, L.F. 1987. The diurnal variability of precipitation across the central Rockies and Adjacent Great Plains. Monthly Weather Review 115:1161-1172.

Trewartha, G.T. 1981. The Earth's Problem Climates. University of Wisconsin Press, Madison, $371 \mathrm{pp}$.

Tucker, D.F. and Li, X. 2009. Characteristics of warm season precipitating storms in the Arkansas-Red River basin. Journal of Geophysical Research 114:1984-2012.

Walters, C.K. and Winkler, J.A. 2001. Airflow configurations of warm season southerly low-level wind maxima in the Great Plains. Part I: Spatial and temporal characteristics and relationship to convection. Weather Forecasting 16:513-530. 